\title{
Agricultura e biodiversidade nas Ciências Sociais brasileiras: alimentando a comunicação entre ciência e políticas públicas
}

\section{Resumo}

O presente artigo decorre de uma reflexão sustentada em dois pressupostos: a) que as ciências e, em particular, as sociais, podem contribuir para informar as tomadas de decisão e a formulação de políticas públicas visando a melhoria da vida das pessoas no planeta e b) que o papel da agricultura na conservação da biodiversidade é uma questão atual de extrema relevância e que merece ser aprofundada. A relação entre a agricultura e a biodiversidade tem sido objeto de questionamentos recentes na sociedade e no campo das políticas públicas. Contudo, se os estudos relacionados à biodiversidade e à agricultura, separadamente, têm observado um considerável crescimento no Brasil, poucos são os investimentos de pesquisa sobre a relação entre esses dois grandes temas. A partir dessas considerações, seguimos dois objetivos principais: 1) investigar como o papel da agricultura familiar na preservação da biodiversidade tem sido abordado pelas Ciências Sociais no Brasil, particularmente nos artigos publicados em periódicos brasileiros nos últimos 20 anos; 2) testar uma metodologia de revisão bibliográfica, criteriosa, que possa ser útil aos tomadores de decisão em políticas públicas e demais interessados.

\footnotetext{
*Antropóloga, professora associada da Universidade Federal Rural do Rio de Janeiro/Curso de Pós-Graduação em Desenvolvimento, Agricultura e Sociedade (CPDA); bolsista de produtividade do Conselho Nacional de Desenvolvimento Científico e Tecnológico (CNPq) e bolsista Cientista de Nosso Estado, Fundação de Amparo à Pesquisa do Estado do Rio de Janeiro (FAPERJ). (Brasil). E-mail: tsrosaprof@yahoo.com.br

** Antropóloga, integrante do Grupo de Pesquisa CINAIS (Ciência, Natureza, Informação e Saberes)
} 
Palavras-chave:Política baseada em evidências. Políticas públicas. Agricultura familiar-biodiversidade. Estado da arte. Comunicação científica.

\title{
Agriculture and biodiversity in Brazilian Social Sciences: fostering communication between science and public policies
}

\begin{abstract}
The present article comes up from a reflection upon what lies in the intersection between two premises: a) that science, and in particular, the social sciences, can contribute towards informing both decision making and the formulation of public policies, aiming at improving the welfare of people in the planet, and, b) that the role of agriculture in the conservation of biodiversity is an extremely relevant contemporary issue, hence the need to study it in greater depth. The relationship between agriculture and biodiversity has been subjected to recent questionings, both in society and in the realm of public policies, as a result of growing concerns about the environmental changes caused by anthropic action. However, despite the increase in number of studies on family-based agriculture, and on biodiversity in Brazil, the research funding available for researching the relationship between those two broad themes is still incipient. Against this backdrop, we shall pursue two main objectives with this study: 1) to investigate how the role of family-based agriculture in the preservation of biodiversity has been approached by the Social Sciences in Brazil, particularly in articles published in Brazilian journals during the latter 20 years and available online; 2) to test a thorough literature review methodology aimed at helping decision makers involved with public policies and others concerned with this issue.
\end{abstract}

Keywords: Family-based agriculture. Biodiversity. Brazilian environmental sociology. Scientific communication. State of the art. Evidence-based policy. 


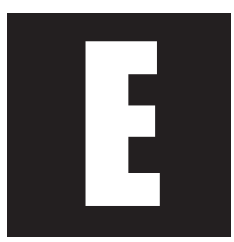

ste artigo apresenta e discute os resultados de um levantamento do conhecimento disponível sobre o papel da agricultura familiar na manutenção da biodiversidade em periódicos brasileiros de ciências sociais.

A metodologia empregada segue, em linhas gerais e com as adaptações necessárias, os procedimentos empregados por instituições de pesquisa adeptas da abordagem conhecida como Evidence-based policy (EBP), que tem por objetivo facilitar o acesso ao conhecimento científico pelos tomadores de decisão em políticas públicas. Preocupados com a qualidade e a eficácia das políticas públicas, pesquisadores comprometidos com essa abordagem sugerem que a formulação de políticas públicas, assim como as decisões a elas relacionadas, sejam informadas por evidências produzidas cientificamente. Como se trata de uma abordagem ainda pouco conhecida no Brasil, consideramos necessária uma rápida explanação sobre o que vêm a ser "Políticas Baseadas em Evidência" (PBE), antes de entrarmos diretamente no objetivo do artigo.

\section{A comunicação entre conhecimento científico e políticas públicas}

A tomada de decisão no âmbito das políticas públicas visando regular ações do Estado que afetam a sociedade civil pode se dar de diferentes maneiras. Informações de origem desconhecida tidas como consensuais, intuição, conhecimento advindo da prática e pressões de grupos de interesse sustentam grande parte das decisões de gestores públicos em diversos âmbitos. Normalmente, a referência a pesquisas ou a consulta a especialistas no embasamento da formulação de uma determinada medida pública, quando ocorre, não é resultado de uma busca sistematizada sobre o tema em questão, mas sim fruto da casualidade e da facilidade 
de acesso a obras e textos científicos ou mesmo a cientistas conhecidos, ocorrendo muitas vezes para validar ou legitimar uma decisão já tomada (Carneiro et al, 2010; Unesco 2010; Laurent et al., 2009a).

Seria ingênuo supor que as decisões políticas seriam tomadas em função de uma racionalidade técnico-científica, ainda que alguns autores sustentem que o maior acesso ao conhecimento científico pelos gestores públicos pode resultar em políticas mais eficazes (Holmes et al., 2008). Não se trata, no entanto, de submeter a decisão política ao argumento científico, mas de ampliar o leque de alternativas e promover uma reflexão crítica de maneira a aprofundar a avaliação sobre as conseqüências da regulação pública sobre a sociedade. No caso específico das políticas voltadas para a manutenção da biodiversidade, sobretudo no que se refere à regulação da atividade agrícola e, consequentemente, da população envolvida, a complexidade das questões debatidas pela sociedade, incluindo setores governamentais, tem apontado para a existência de uma grande lacuna entre o conhecimento científico disponível e a decisão política. A necessidade de construção de vias de comunicação entre esses dois campos tem sido um tema bastante debatido, tanto na esfera acadêmica como na governamental de diferentes países.

Desde a década de 1990, alguns governos e organismos internacionais têm procurado institucionalizar o recurso sistemático ao conhecimento baseado em evidências ${ }^{1}$, o que ficou conhecido na língua inglesa como Evidence based policy - EBP ou Evidence based decision - EBD (Da-

1 Diversos organismos, tais como o Banco Mundial, a Organização Mundial da Saúde e a Organização das Nações Unidas para Agricultura e Alimentação (FAO), têm recorrido a esse método. No campo da governança ambiental internacional, especificamente, vale a pena mencionar o Painel Intergovernamental sobre Mudanças Climáticas (IPCC), o Clearing House Mechanism (CHM) e a Plataforma Intergovernamental Ciência-Política sobre Biodiversidade e serviços de Ecossistemas (IPBES). 
vies et al., 2001 e Laurent et al., 2009b). ${ }^{2}$ Países como Inglaterra, Estados Unidos, África do Sul, entre outros, têm criado instituições encarregadas de colocar em prática mecanismos para facilitar o uso criterioso dos conhecimentos científicos nas decisões públicas. Dentre os mecanismos empregados por estes governos e outras instituições adeptas da PBE, os mais referenciados são a elaboração de estados da arte sistematizados, elaboração de meta-análises e divulgação de bases de dados bibliográficos na internet. No entanto, essa comunicação nem sempre é fácil, haja vista os desafios colocados pelas diferenças entre os modos de fazer e o tempo de trabalho característicos da ciência e da política, as dificuldades de compreensão da linguagem científica, a falta de prática de busca em bases de dados pelos gestores públicos, a dificuldade de ampliar para outras áreas o conhecimento produzido sobre uma realidade específica, etc. (Carneiro et al., 2010; Laurent et al. 2009a; Holmes et al, 2008).

A elaboração de metaconhecimentos a partir de questões específicas propostas por um gestor público é um instrumento que visa suprir a dificuldade de tempo desse público para consultas em bases de dados. Este procedimento deve ser sustentado em uma metodologia rigorosa de levantamento bibliográfico sistemático, guiado por uma questão previamente definida, considerando que, quanto mais específica for a questão, mais fácil será a realização do levantamento e a subseqüente produção de metaconhecimentos sobre o assunto (Sutherland et al., 2004). Trata-se, primeiramente, de saber formular adequadamente uma questão, o que recoloca em outros termos as dificuldades de comunicação entre o corpo de especialistas e os gestores públicos, pois nem sempre a questão que interessa a este público é passível de ser traduzida em um objeto científico. Isso pode dificultar a realização de revisões sistemáticas e fomentar posturas criticas à PEB, como já observaram Nutley et al (2002) e Davies et al (2001).

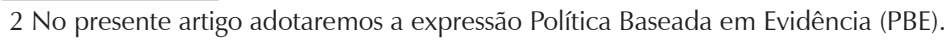


O objetivo central dessa metodologia reside, portanto, não apenas em produzir uma síntese de boa qualidade que possa ser útil aos gestores públicos, mas também em como tornar esse conhecimento disponível para eles. Isso requer que se tenha um conhecimento também da política, como lembra Hoppe: the more and better knowledge of policy, the easier it is to mobilize knowledge production for and application in policy (2005, p.202). As limitações da ciência para dar conta de novos problemas colocados pelas crescentes incertezas do conhecimento - particularmente sobre as questões ambientais - e, por outro lado, a crescente produção de artigos científicos são outra dimensão do mesmo desafio. No momento não entraremos em detalhes sobre a eficácia e o uso dessa metodologia, sendo o objetivo aqui apresentar o estado da arte do debate sobre o tema do papel da agricultura familiar na conservação da biodiversidade. Contudo, a motivação para a realização de tal levantamento bibliográfico assim como os procedimentos e a reflexão que se seguem foram informados pela abordagem da Política Baseada em Evidências. Em relatório recentemente publicado sobre o estado da arte das Ciências Sociais no Mundo, (Unesco, 2010), a UNESCO chama a atenção para o interesse crescente nas decisões baseadas em evidências, o que aponta para uma mudança de orientação no uso do conhecimento na decisão política: os gestores públicos estão mais interessados em evidências transparentes e claras sobre o que funciona em determinados contextos e por quê do que em estudos mais genéricos (idem, 317). A questão polêmica levantada é sobre a capacidade das Ciências Sociais em informar as políticas públicas devido à especificidade dos contextos em que os pesquisadores trabalham e dos limites de generalização de suas conclusões, o que remete a outra questão: a da possibilidade de se fazer uso de conhecimentos já produzidos e disponíveis ou, em outras palavras, da necessidade de se adequar os objetivos da pesquisa aos da política. O emprego das Ciências Sociais na abordagem das políticas baseadas em evidência enfrenta outro limite, que é o próprio sentido de evidência. O que pode ser considerado evidência na pesquisa social? O que é evidên- 
cia em um dado contexto vale para outro? É possível separar as evidências apresentadas em uma pesquisa da pergunta que as produziu? Tais questões, sem dúvida, merecem uma reflexão aprofundada de maneira a levar em conta a especificidade do fazer científico das Ciências Sociais sem, contudo, comprometer o seu rigor.

Outro complicador surge quando nos dispomos a realizar uma revisão em Ciências Sociais sobre uma questão como a que nos ocupamos no presente artigo, que abrange discussões e conceitos de outras disciplinas, como é o caso do conceito de biodiversidade, cunhado pela Biologia. É nesse sentido que se aceita, quase como um consenso, que o estudo de questões ambientais envolve a interlocução com diferentes áreas do conhecimento. A interdisciplinaridade tem sido colocada como uma necessidade e até mesmo como a única possibilidade de produzir um conhecimento criterioso sobre a problemática ambiental, muitas das questões levantadas não podendo ser suficientemente desenvolvidas quando se recorre unicamente às ciências sociais ou às naturais. Essa característica também está presente no levantamento bibliográfico sistematizado que apresentamos neste artigo, à qual voltaremos mais tarde.

\section{Porque investigar a relação entre agricultura familiar e biodiversidade?}

Como parte de um projeto internacional sobre o tema da Agricultura e Desenvolvimento Sustentável ${ }^{3}$, o levantamento bibliográfico foi orientado por uma questão em consonância com esse projeto: o papel da agricultura familiar na conservação da biodiversidade. A escolha dessa questão se justifica também por alimentar um debate político e acadê-

3 Referimo-nos aqui ao projeto de pesquisa Agricultura e desenvolvimento sustentável nas problemáticas das 'Políticas baseadas em evidências' envolvendo estudos de caso na França, no Brasil e na África do Sul, financiado pela ANR (Agência Nacional de Pesquisa), CNPq e Faperj. 
mico controverso, com repercussão na formulação de políticas públicas ambientais e no cotidiano das populações afetadas. Por exemplo, a chamada agricultura tradicional é tida, de um lado, como uma das principais responsáveis pelo declínio da biodiversidade e, de outro, como estimuladora da biodiversidade, como veremos abaixo.

Percorrendo uma trajetória histórica de exclusão e invisibilidade pelas políticas públicas agrícolas e agrárias, a agricultura familiar só entrou no debate político e foi reconhecida como forma peculiar de produção e beneficiária de uma política específica no Brasil em 1996, com a elaboração do Programa Nacional de Fortalecimento da Agricultura Familiar - PRONAF (Carneiro, 1997; Leonard et al., 2009). Além de quebrar o mito do atraso e da ausência de peso econômico dessa forma de produção, que até então era reconhecida como "pequena", o debate que se seguiu à implementação dessa política chamou a atenção também para a possibilidade de a forma de produção agrícola familiar de pequena escala ser mais sustentável em termos econômicos, sociais e ambientais. No entanto, opinião contrária é defendida por alguns pesquisadores e pelo setor do agronegócio, com eco no Ministério da Agricultura que sustenta ser a grande produção com base no uso de tecnologias avançadas mais racional em termos econômicos e ambientais.

\section{Procedimentos metodológicos ${ }^{4}$}

O levantamento bibliográfico realizado teve o objetivo também de testar uma metodologia francamente utilizada em outros países, mas aplica-

\footnotetext{
4 O levantamento bibliográfico apresentado aqui foi realizado em 2007 por Camila Medeiros, e atualizado por Thais Danton em 2010, ambas pesquisadoras do Grupo de Pesquisa CINAIS/ UFRRJ (www.ufrrj.br/cpda/cinais). Além desse, foram feitos levantamentos semelhantes nos periódicos de Economia por Andrea Rente e Sandro Leão, coordenado por Sergio Leite, e nas teses dos programas de Ciências Sociais (Cf. Da-Silva-Rosa et. al., 2010).
} 
da principalmente a outras áreas que não as Ciências Sociais. Esta metodologia se baseia, como mencionado acima, na aplicação de procedimentos criteriosos de busca e de seleção do material consultado - artigos, no nosso caso - levando-se em conta dois critérios na seleção do material: a conformidade com a questão em foco e a qualidade da validação empírica ${ }^{5}$.

Para realizar uma revisão sistemática nas Ciências Sociais a partir da questão definida, procedeu-se uma busca na base de dados eletrônica WebQualis ${ }^{6}$, da CAPES, pelos periódicos das três áreas de interesse para nosso estudo: Antropologia, Ciência Política e Sociologia. Devido ao caráter desse levantamento, realizado com poucos recursos humanos e materiais, decidiu-se limitar o universo da pesquisa de maneira a torná-lo realizável. Como primeiro passo, estabeleceu-se como critério de corte os conceitos atribuídos aos periódicos pelo próprio sistema de avaliação da CAPES, o Qualis, sendo selecionados os periódicos classificados como de nível "A" e nível "B" com circulação "Internacional" e "Nacional". Segundo a CAPES, tal classificação expressa uma hierarquia que tem por base um padrão de qualidade dos artigos publicados pelos periódicos, sendo o nível A de circulação internacional o mais elevado, comparado ao padrão internacional dos melhores periódicos. Seguiram na escala hierárquica os classificados como B de circulação nacional, B de circulação local e finalmente os periódicos de nível $\mathrm{C}$, menos $\operatorname{cotados}^{7}$.

\footnotetext{
5 Revisões sistemáticas de temas específicos relacionados à conservação ambiental, e também um Guia para a produção deste tipo de síntese, podem ser resgatados no site do Centre for Evidence-Based Conservation: http://www.cebc.bangor.ac.uk/.

6 Conforme a página eletrônica da Capes, "Qualis é o conjunto de procedimentos utilizados pela Capes para estratificação da qualidade da produção intelectual dos programas de pósgraduação. [...] Como resultado, disponibiliza uma lista com a classificação dos veículos utilizados pelos programas de pós-graduação para a divulgação da sua produção. [...] A classificação de periódicos é realizada pelas áreas de avaliação e passa por processo anual de atualização". http://www.capes.gov.br/avaliacao/qualis (em 30/08/10)

7 Nas listagens disponíveis em 2007 no WebQualis, estes eram classificados por nível A, B ou C, segundo avaliação do corpo editorial, seguido do critério de circulação (Internacional,
} 
Contudo, apesar dos avanços na produção acadêmica em sociologia ambiental, ainda se observa uma resistência, já apontada por Ferreira (2004a), por parte de setores fortemente disciplinares das Ciências Sociais brasileiras. Isso se expressa na pouca quantidade de artigos publicados sobre o tema nos periódicos mais conceituados, o que nos levou a incluir periódicos com classificação mais baixa, desde que suas linhas editoriais fossem especificamente relacionadas ao tema em questão.

A base WebQualis apresentou em 2007 um total de 627 periódicos nas áreas selecionadas. Após aplicados os nossos critérios de seleção, restaram 50 (tabela 1). Como cada uma dessas áreas tem a sua própria classificação, alguns periódicos constaram repetidamente nas três áreas e, muitas vezes, com avaliações distintas. De acordo com informação disponível na página eletrônica da Capes ${ }^{8}$,

o mesmo periódico, ao ser classificado em duas ou mais áreas distintas, pode receber diferentes avaliações. Isto não constitui inconsistência, mas expressa o valor atribuído, em cada área, à pertinência do conteúdo veiculado. Por isso, não se pretende com esta classificação, que é específica para o processo de avaliação de cada área, definir qualidade de periódicos de forma absoluta.

Para neutralizar a dupla ou tripla inserção de um mesmo periódico, tomamos como referência a classificação da área da Sociologia, desconsiderando-se a classificação nas outras áreas. No entanto, foi respeitada a inserção de origem dos periódicos estritamente disciplinares. ${ }^{9}$ Como a consulta foi

Nacional, Local). Esses critérios foram modificados pela CAPES em 2009, mas nosso levantamento manteve a seleção de periódicos já realizada com critérios vigentes em 2007. http:// qualis.capes.gov.br/webqualis/

8 www.capes.gov.br/avaliacao/qualis (acessado em 16 de agosto de 2010)

9 Foram excluídos os periódicos específicos de Arqueologia que se encontram classificados junto com a Antropologia, e outros que, embora incluídos nas listagens das três áreas de conhecimento, são afins a outras áreas, como Psicologia, Direito, Serviço Social, entre outros. 
feita pela internet, foram excluídos os periódicos que não disponibilizavam os sumários on line. Foram excluídos também os títulos que já constavam na base de Economia tais como: Agricultura em São Paulo: Revista de Economia Agrícola; Estudos Econômicos; Nova Economia; Organizações Rurais e Agroindustriais; Revista de Economia e Sociologia Rural; Revista de Economia Política que foram objeto de levantamento do mesmo tipo ${ }^{10}$.

Tabela 1. Distribuição dos periódicos segundo a área de conhecimento

\begin{tabular}{c|c|c}
\hline Área de conhecimento & $\begin{array}{c}\text { Total de Periódicos } \\
\text { WebQualis/Capes }\end{array}$ & $\begin{array}{c}\text { Total de periódicos } \\
\text { considerados }\end{array}$ \\
\hline Antropologia & 88 & 5 \\
\hline Ciência Política & 97 & 4 \\
\hline Sociologia & 442 & 41 \\
\hline TOTAL & $\mathbf{6 2 7}$ & $\mathbf{5 0}$ \\
\hline
\end{tabular}

Para a localização dos 50 periódicos selecionados, utilizou-se a base Scielo (www.scielo.br) e o portal de periódicos da Capes ${ }^{11}$. Quando não encontrados nestas páginas, lançou-se mão do site de busca Google ${ }^{12}$. A pesquisa cobriu os números publicados entre $1990^{13}$ e 2010 . A seleção dos artigos foi realizada por uma busca no título pelas seguintes palavraschave: agricultura, sustentabilidade/desenvolvimento sustentável (quando

10 Esse levantamento seguiu os mesmos critérios aqui explicitados, foi realizado por Sandro Leão e Andréia Rente, sob a coordenação do professor Sergio Leite.

11 Enquanto o portal de Periódicos da Capes direciona para a página do periódico procurado, o Scielo disponibiliza artigos de revistas variadas (artigos estes que, em alguns casos, não se encontram na íntegra na própria página do periódico, quando existente).

12 A pesquisa contemplou também alguns poucos periódicos que não disponibilizavam os resumos e/ou artigos na íntegra, mas que puderam ser consultados (e eventualmente fotocopiados) quando disponíveis em bibliotecas da cidade do Rio de Janeiro.

$13 \mathrm{O}$ ano de 1990 foi escolhido como ponto de partida do levantamento em função da realização da Rio 92 que fomentou a produção das Ciências Sociais sobre os temas ambientais. 
referidas à agricultura e/ou meio ambiente), unidades de conservação, biodiversidade, natureza/natural, ambiente/ambiental, desenvolvimento rural/rural ${ }^{14}$. Esse procedimento também foge dos indicados pelos parâmetros da revisão sistemática sugeridos pelo CEBC, que sugere uma varredura a mais ampla possível, incluindo até mesmo artigos não publicados e sem se limitar à busca por palavras-chaves.

Resumidamente, o processo de seleção de artigos a serem analisados na revisão percorreu três etapas: (1) leitura de cada um dos 12. 295 títulos dos artigos apresentados nos sumários de cada número de cada periódico, em busca da ocorrência de alguma das palavras-chave ${ }^{15}$, o que resultou em 295 artigos; (2) leitura dos resumos desses 295 artigos, selecionando dentre estes os considerados pertinentes à questão da pesquisa, mesmo que indiretamente, o que resultou em 18 artigos (3) leitura dos 18 artigos selecionados distribuídos em: 1 de Antropologia, e 17 de Sociologia (ver tabela 2). Foram descartados artigos que se referiam a pesquisas realizadas em outros países ou em outros períodos históricos.

14 Estas foram consideradas separadamente, sem cruzamentos; ou seja, se qualquer uma delas aparecesse no título, resumo ou palavras-chave, o artigo era selecionado.

15 No caso dos título de artigos que não apresentavam nenhuma das palavras-chaves, prosseguiu-se a busca no resumo e nas palavras-chave do artigo (quando disponíveis). 
Tabela 2. Total de periódicos e artigos consultados no portal WebQualis segundo a área de conhecimento

\begin{tabular}{c|c|c|c|c|c}
\hline $\begin{array}{c}\text { Área de } \\
\text { conhecimento }\end{array}$ & $\begin{array}{c}\text { Total de } \\
\text { periódicos } \\
\text { consultados }\end{array}$ & $\begin{array}{c}\text { Total de } \\
\text { números } \\
\text { consultados } \\
\text { (sumários) }\end{array}$ & $\begin{array}{c}\text { Total de artigos } \\
\text { consultados } \\
\text { (título, palavras- } \\
\text { chave; resumos) }\end{array}$ & $\begin{array}{c}\text { Total de } \\
\text { artigos pré- } \\
\text { selecionados } \\
\text { (palavras- } \\
\text { chave) }\end{array}$ & $\begin{array}{c}\text { Total de } \\
\text { artigos } \\
\text { selecionados } \\
\text { para análise }\end{array}$ \\
\hline Antropologia & 5 & 98 & 955 & 17 & 1 \\
\hline $\begin{array}{c}\text { Ciência } \\
\text { Politica }\end{array}$ & 4 & 93 & 610 & 25 & 0 \\
\hline Sociologia & 41 & 1.021 & 10.730 & 253 & 18 \\
\hline TOTAL & $\mathbf{5 0}$ & $\mathbf{1 . 3 1 0}$ & $\mathbf{1 2 . 2 9 5}$ & $\mathbf{2 9 5}$ & $\mathbf{1 9}$ \\
\hline
\end{tabular}

\section{Conteúdo do conhecimento disponível}

A leitura da bibliografia levantada foi orientada por um conjunto de questões: quais os argumentos desenvolvidos pelos autores a respeito do nosso tema? A que tipo de instrumental analítico recorrem, para embasar seus argumentos? Qual o universo empírico a que se referem? Tentou-se também verificar a produção de evidências. Ainda que o sentido dessa noção nas Ciências Sociais seja bastante problemático, como foi colocado acima, buscou-se identificar se os artigos baseavam seus argumentos em algum tipo comprovação empírica. A leitura foi sistematizada em uma ficha, com objetivo de padronizar as informações do conjunto dos artigos e também para servir de protótipo de um instrumento de sistematização do conhecimento, com vistas à produção futura de sínteses a serem disponibilizadas na página eletrônica do grupo de pesquisa ${ }^{16}$.

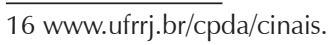


A primeira observação a ser feita é que, embora os artigos tenham sido selecionados por fazerem referência, mesmo que indireta, à questão formulada por nós, a maior parte deles não tinha nesse tema o seu fio condutor. As menções ao papel atribuído à agricultura familiar na manutenção da biodiversidade encontravam-se, quase sempre, dispersas ao longo dos textos, ou implícitas em outras questões abordadas, como foi o caso, por exemplo, dos artigos que tratavam da situação das "populações tradicionais" em áreas de conservação.

Dessa sistematização, resultou um conjunto de questões de ordem metodológica ou de conteúdo temático que agrupam distintamente os artigos, de modo que um mesmo artigo pode estar referido em mais de uma questão. ${ }^{17}$

\section{A multidisciplinaridade da autoria}

Apesar de a seleção dos artigos ter sido feita em periódicos registrados nas áreas de Ciências Sociais do WebQualis da CAPES, observou-se que alguns autores não tinham formação em ciências sociais em nenhum nível. É o caso de Almeida (2006), Floriani (2007), Martins (2005), Paterniani (2001), Pedlowski et al. (1999), Queiroz (2005), Rodrigues et al. (2003) e Silva (2009) . Este fato poderia sugerir um desvio do objetivo da análise cujo interesse centrava-se na produção das ciências sociais. Contudo, decidimos considerar os artigos desses autores tendo em vista contemplar o debate interdisciplinar. Além disso, pareceu-nos arbitrário excluir artigos de especialistas de outras áreas disciplinares que tinham sido aceitos em periódicos com circulação entre os cientistas sociais e reconhecidos pelo sistema Qua-

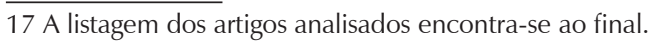


lis da Capes. Essa aproximação entre áreas tais como Biologia, Agronomia, Geografia, Sociologia e Antropologia, reforça a dimensão interdisciplinar da problemática ambiental já apontada por diversos autores (Da-Silva-Rosa et al., no prelo). No entanto, é difícil afirmar que tenha ocorrido um diálogo entre os autores com base na troca de conhecimentos e buscando a convergência de estruturas teóricas com o propósito de construir uma nova abordagem que poderia vir a constituir um novo campo de conhecimento, como sugere Leff (2001) a respeito de um saber ambiental. Entre os artigos selecionados, 7 foram escritos somente por autores com formação integral em Ciências Sociais, 4 por autores com formação em diferentes disciplinas e 7 por autores com formação em outras disciplinas, principalmente na agronomia. Torna-se evidente, assim, que nossa questão instiga pesquisadores de diferentes campos de conhecimento.

\section{Objetividade x subjetividade}

O debate sobre o impacto de "populações tradicionais", incluindo aí os pequenos agricultores familiares, sobre a biodiversidade, em particular em áreas de conservação ambiental, se apresenta, de modo geral, carregado de emoções, como já foi observado (Ferreira, 2004b; Gerhardt, 2008). Mais do que apresentar evidências empíricas que sustentem os argumentos, os autores tendem a polarizar o debate expressando opiniões favoráveis ou contrárias à dimensão conservacionista da agricultura familiar sem, contudo, confrontar suas interpretações com posições contrárias ou apresentar provas consistentes. Alguns artigos não apresentam explicitamente o material empírico sobre o qual sustentam seus argumentos, mesmo aqueles que se baseiam em estudos de caso ou em pesquisas empíricas realizadas pelo próprio autor ou por terceiros. Observou-se a ausência de rigor na apresentação da validação empírica conforme os 
padrões comuns a outras áreas disciplinares, especificamente nas ciências naturais. Esta característica acrescentou outra dificuldade à implementação das diretrizes para revisões sistemáticas, a qual incita a reflexão sobre os limites e a validade da recorrência às ciências sociais para fins de PBE.

\section{A agricultura tradicional (ou sistema de pousio) como uma prática sustentável}

A principal controvérsia sobre o impacto da agricultura praticada por pequenos agricultores familiares sobre o meio ambiente se refere à especificidade da agricultura itinerante. Às "populações tradicionais", em suas diferentes conformações, é atribuída a prática do sistema de pousio que consiste em deixar uma parte da área agricultável "em descanso" para recuperar a fertilidade do solo, enquanto se trabalha em outras áreas. Algum tempo depois, que varia por região, a vegetação é derrubada e, em alguns casos, segue-se a queima da vegetação mais rala para então preparar o solo para o plantio. Essa técnica que alguns consideram herdada dos índios brasileiros, outros dos africanos trazidos como escravos, é bastante disseminada tanto no litoral (pelos caiçaras) como no interior do país (pelos caboclos, caipiras, sertanejos etc).

A derrubada da vegetação e, mais ainda, a queimada têm sido interpretadas na aplicação da legislação ambientalista como "ameaça à regeneração da floresta" o que tem levado os fiscais ambientais a acionar um conjunto de medidas repressoras aos agricultores. Para os que advogam o modelo de preservação ambiental sem a presença humana, esse é um dos mais fortes argumentos em que se apoiam para justificar a ameaça à biodiversidade que tais práticas representam. De outro lado, alguns estudiosos argumentam justamente o contrário ao sustentarem que certas populações humanas contribuem para o aumento da variabilidade das plantas, 
através de suas práticas agrícolas que implicam também a troca de espécimes entre grupos sociais de distintos lugares, especialmente as plantas alimentícias básicas da população rural, como é o caso da mandioca. O sistema de pousio aqui é tido como responsável pela maior variabilidade primária no âmbito da roça, afirma Martins ${ }^{18}$ (2005, p. 216). Apoiado em estudos de Genética sobre as variedades de mandioca encontradas nas roças pesquisadas (na Mata Atlântica e na Amazônia), esse autor conclui que as populações humanas tradicionais não apenas são mantenedoras da diversidade genética como geram e amplificam a variabilidade num processo contínuo (Martins, 2005, p. 218).

Autores como Arruda' ${ }^{19}$ (1999), Dumora ${ }^{20}$ (2006), Rodrigues ${ }^{21}$ et al. (2003) e Silva ${ }^{22}$ (2009) apresentam argumentos similares aos do geneticista na defesa do papel conservacionista das "populações tradicionais", mas não se sustentam em resultados de pesquisa desenvolvidos por eles próprios. Recorrem a fontes secundárias, algumas delas citadas repetidamente, tais como Gomez-Pompa et al. (1990), Posey (1986), Balée (1988 e 1989) para corroborar suas posições em defesa do que denominam de agricultura rudimentar. É o que acontece com Arruda (1999), que reforça as conclusões de Martins, sem citá-lo, contudo, ao afirmar que a variabilidade induzida pelo homem no meio ambiente tropical (principalmente através da agricultura itinerante e do adensamento de espécies úteis) favoreceu e favorece a diversidade biológica e o processo de especiação (Arruda, 1999, p. 87). Recorrendo a fatores históricos, como a dinâmica da colonização do

\footnotetext{
18 Paulo Sodero Martins foi professor do Departamento de Genética da ESALQ/USP (Escola Superior de Agricultura Luiz de Queiroz). Destacou-se pela ênfase na multidisciplinaridade para a compreensão da evolução e da genética ecológica.

19 Rinaldo Arruda é doutor em ciências sociais.

20 Catherine Dumora é antropóloga

21 Aníbal Rodrigues é doutor em Desenvolvimento e Meio Ambiente

22 Carlos Eduardo Mazzetto Silva é engenheiro agrônomo e doutor em Geografia.
} 
Brasil, e culturais, como o da herança indígena, explica a "adaptação" das "sociedades tradicionais" ao meio ambiente por meio da elaboração de um extenso e minucioso conhecimento dos processos naturais, sendo até hoje, as únicas práticas de manejo adaptadas às florestas tropicais (Arruda, 1999, p. 83). A situação de comunidades humanas em regiões isoladas do país teria forçado-as a essa adaptação no que se refere ao uso dos recursos naturais e às práticas agrícolas. Por sociedades tradicionais, o autor identifica as comunidades caiçaras, os sitiantes e roceiros tradicionais, comunidades quilombolas, comunidades ribeirinhas, os pescadores artesanais, os grupos extrativistas e indígenas que se distinguiriam pelo isolamento, formas de cooperação social e relações sustentáveis no manejo da natureza. Ao enfatizar o potencial conservacionista desses segmentos populacionais, Arruda se contrapõe às abordagens tecnicistas e desenvolvimentistas que enxergariam nessas culturas e práticas agrícolas um exemplo de atraso ou de resistência ao desenvolvimento. Ao contrario, o autor sustenta que tais culturas rústicas, assim como as indígenas, deveriam servir de inspiração para um manejo sustentado do meio ambiente (Arruda, 1999, p. 90).

Argumento semelhante é sustentado por Silva (2009). Recorrendo à noção de sociobiodiversidade, esse autor contrapõe modelos sustentáveis de ocupação, produção e geração de riquezas implementados pelas comunidades tradicionais do Cerrado ao modelo do agronegócio, que usa os recursos naturais e o espaço como um negócio (mercadoria) (Silva, 2009, p. 99). Com base em ampla pesquisa bibliográfica, imagens de satélite e informações de pesquisas realizadas por ele próprio, Silva pretende demonstrar como as comunidades tradicionais e comunidades rurais mestiças (camponesas) conseguiram se manter por um longo período no Cerrado sem provocar quase nenhuma alteração na sua fisionomia natural. O mesmo tipo de fonte é usado por Rodrigues et al. (2003) como evidência empírica do baixo impacto ambiental causado pelos agricultores familiares na região 
de Mata Atlântica em Guaraqueçaba, no estado do Paraná. Recorrendo a imagens de satélite, os autores argumentam que em 1999, a pequena agricultura, praticada há décadas na região, ocupava 7,9\% do território municipal, enquanto que $91,4 \%$ da área era coberta por floresta. Tais dados são utilizados como evidência da sustentabilidade do sistema de pousio praticado no local, argumento este reforçado com a referência a autores como Diegues (1996) e Harwood (1996), que questionam o efeito nefasto dessa prática agrícola para o meio ambiente: há indícios de que essa atividade, se adequadamente praticada, pode incrementar a biodiversidade e contribuir para um maior grau de sustentabilidade dos sistemas agrícolas (Harwood, 1996 citado por Rodrigues et al. 2003, p. 122).

A defesa do sistema de pousio como prática sustentável conduz, em muitos casos, a uma critica à esfera pública (e à legislação ambiental por ela elaborada) acusada de desconhecer o real impacto dessa prática sobre o meio ambiente e o conhecimento empírico tradicional que o sustenta. Dumora lembra que mesmo quando pretensamente protegida por meio da criação de uma Área de Proteção Ambiental, justificada pela presença e necessidade de preservação de comunidades caiçaras, as práticas de pousio, base de toda a organização produtiva e social dessas comunidades, foram reprimidas (Dumora, 2006; Teixeira, 2005). Estas contradições entre o discurso de fundo da legislação ambiental e a fiscalização exercida pelos órgãos ambientais são tidas como fonte de vários conflitos e relações tensas entre estes e as populações das áreas protegidas. $\mathrm{O}$ argumento quanto ao desconhecimento da legislação sobre as evidências científicas da contribuição da agricultura de corte e queima ao incremento da biodiversidade, evocado na obra mais conhecida de Diegues (1996), é ecoado em diversos autores.

Apesar da ênfase na diversidade social, cultural e ambiental dessas comunidades, o que pressupõe modos de apropriação da natureza e de organização social diferenciados, os argumentos apresentados não 
chegam a romper com uma abordagem dualista onde, de um lado, estaria a diversidade das comunidades tradicionais, unificadas pelo modo sustentável de relação com a natureza e por uma lógica não mercantil de apropriação dos recursos naturais e, de outro, um todo indiferenciado reconhecido como agronegócio. Essa dualidade está no cerne do debate, polarizando-o em duas posições antagônicas: de um lado a defesa das populações tradicionais e, de outro, o argumento favorável aos grupos de produtores orientados pela racionalidade técnica, sendo este minoritário na bibliografia consultada. O fato mesmo da ocorrência dessa polarização expressa uma característica desse debate marcado muito mais por defesas de posições acaloradas, emocionais, do que pela apresentação de provas que sustentem cientificamente a argumentação.

O debate inclui também uma discussão semelhante, mas cujo foco de observação não está diretamente sobre a agricultura familiar, mas no extrativismo vegetal. Como a maioria dos grupos extrativistas pratica, com maior ou menor intensidade, uma pequena agricultura voltada para o auto-consumo, e como muitos dos agricultores familiares recorrem a alguma forma de extrativismo, consideramos que a situação dessas duas categorias sociais em relação ao meio ambiente e à sociedade é estruturalmente equivalente, o que nos levou a incorporá-la à análise.

A relação dos grupos extrativistas com o meio ambiente passa pela questão do uso comum de recursos naturais, o que leva ao questionamento de noções, muitas vezes implícitas na análise, de propriedade privada e apropriação individual dos bens naturais. Azevedo et al. (2009) desenvolvem esse tema com base na teoria dos bens (Ostrom, 1990) aplicada em estudos de caso realizados em duas localidades do cerrado mineiro. Recorrendo também a dados secundários originários de estudos realizados em regiões e contextos ambientais distintos, os autores se contrapõem à idéia da tragédia dos recursos comuns ("the tragedy of the commons") 
desenvolvida por Hardin (1968). Ao contrário da inevitável destruição ambiental observada por Hardin nos campos de pastagens abertos, Azevedo et al. argumentam que o esgotamento dos recursos naturais em áreas de uso coletivo seria decorrência do esfacelamento dos grupos sociais pela submissão à lógica de produção capitalista, intensiva e predatória, além de estranha ao grupo. Nessa direção, os autores vão buscar nos arranjos coletivos dos grupos extrativistas os princípios explicativos para a eficácia ambiental da exploração extrativista do pequi nas localidades observadas. Algo similar é proposto por Mota et al. (2008), baseado em pesquisa sobre as coletoras de mangaba no estado do Sergipe. Ao chamar atenção para o papel desempenhado por este grupo como agente no processo de desenvolvimento sustentável, as autoras também criticam os gestores públicos pela falta de conhecimento sobre as formas de manejo dos recursos naturais praticadas por grupos deste tipo. Entendem ainda que a necessidade de se preservar os recursos naturais, dada a sua "importância para a sobrevivência", pode levar os grupos extrativistas a experiências de institucionalização de determinados arranjos (comportamentos individuais ou comunitários) que são responsáveis pelo uso regulado e não predatório dos bens naturais. Observam que a dinâmica da vida social está atrelada aos ciclos da natureza na medida em que a reprodução social das comunidades depende da continuidade dos recursos naturais que elas usam. Nesse sentido, reforçam a importância dos conhecimentos tradicionais, assim como os científicos, para a formulação das políticas públicas.

\section{Uma crítica ao estilo ensaístico} dos estudos ambientais nas ciências sociais

A necessidade de mais estudos em profundidade sobre o uso que certas populações fazem dos ecossistemas, com vistas a compreender me- 
Ihor sua diversidade e os critérios de sustentabilidade, é observada por Lima et al. (2005), Ferreira (2004b) e Castro et al. (2006). Essa demanda por abordagens empíricas no lugar de meras suposições reflete a preocupação destes autores acerca de uma percepção naturalizada que vê as "populações tradicionais" como intrinsecamente sustentáveis e organicamente em harmonia com o meio ambiente. Os autores citados rejeitam este pressuposto argumentando que o mesmo não leva em consideração a dinâmica interna e a história de cada comunidade. Com esta crítica, os autores enfatizam a necessidade de se romper com a dualidade que associa o tradicional à sustentabilidade e o moderno à degradação ambiental. Esta oposição, tida como generalizante e superficial, é criticada por estar baseada em um falso paradigma: a reificação do tradicional reconhecido como intrínseco às práticas agrícolas das pequenas comunidades. Tal crítica aponta para a necessidade de ampliar os estudos empíricos que apresentem com maior rigor os resultados de pesquisa, de maneira a se contrapor às análises sustentadas em posições político-ideológicas.

\section{A sustentabilidade da agricultura familiar não é intrínseca}

Como alternativa à percepção essencialista que atribui a determinadas culturas ou grupos sociais um comportamento intrinsecamente "conservacionista", alguns autores apresentam outros critérios para explicar seja a sustentabilidade de determinados modos de vida ou práticas sociais, seja o sucesso de projetos e medidas de conservação ambiental em dadas localidades. Critérios esses que incluem a orientação econômica da produção (Lima et al., 2005; Rodrigues et al., 2003), as características da formação social do grupo, a existência de uma cultura ecológica (Lima et al., 2005) e arranjos político-institucionais locais (Ferreira, 2004b; Castro et al., 2006). 
Para Lima et al. o grau de dependência do grupo ao mercado interfere em seu grau de sustentabilidade. É possível dizer que o argumento desses autores pressupõe a ideia de um continuum onde as pontas seriam ocupadas, de um lado, por economias mais independentes do mercado - autóctones - representada pelas populações indígenas e, de outro, a economia de orientação lucrativa representada pelas empresas que visam a acumulação capitalista. Com base nas categorias sociais do meio rural amazônico, constroem uma escala em que o espaço intermediário entre os mais sustentáveis (orientação econômica autóctone) e os menos (orientação lucrativa), seria ocupado pelos grupos de orientação consuntiva (pautados pelo consumo) que, também centrados na satisfação das necessidades do grupo doméstico, como os autoctónes, se relacionariam com o mercado somente para adquirir bens indispensáveis à sua reprodução. Em posição equivalente estariam as oligarquias tradicionais, que recorreriam ao mercado para garantir o seu conforto (Lima et al., 2005). A cada um desses tipos de orientação econômica corresponderiam culturas ecológicas (valores, percepções e conhecimentos ambientais) diferenciadas que informariam as práticas em relação ao mercado. Contudo, ainda que em alguns momentos os autores pareçam oscilar ora para uma abordagem mais mercadológica, ora mais culturalista, eles têm o cuidado de recusar uma visão determinista optando por uma orientação mais holística ao considerar que os comportamentos dos grupos sociais sobre o meio ambiente estão relacionados a uma conjugação particular de suas características sociais em um dado momento e lugar (Lima et al., 2005, p. 50), chamando a atenção assim para a dimensão multicausal e histórica dessa relação.

Numa visão crítica ao modelo analítico que reconhece na orientação para o mercado um critério de insustentabilidade da produção, Almeida (2006), argumenta que a opção de pequenos agricultores pela agricultura orgânica, mais conservacionista em detrimento da agricultura 
convencional, pode ser pautada por uma lógica comercial orientada pelo desejo de aumentar os ganhos. Além disso, podem ser motivados por uma preocupação com a própria saúde, o que foi também observado por Brandenburg et. al. (2004), que pesquisou a mesma região estudada por Almeida (área metropolitana de Curitiba). Há, nestes autores, uma crítica implícita à abordagem culturalista que interpreta a atitude de grupos sociais tidos como tradicionais ou coletores como ecologicamente correta. Reforçando esta crítica, Allegretti (2008) argumenta que o combate ao desmatamento empreendido pelos seringueiros através dos empates ${ }^{23}$ não pode ser atribuída a uma concepção abstrata de natureza (...); o questionamento ao desmatamento não se dava por razões ambientais, mas por motivos sociais e econômicos, na medida em que dependiam para viver de uma floresta que estava sendo derrubada (2008, p. 45). Nesse caso, os seringueiros se aproximam dos movimentos ambientalistas, mas não podem ser confundidos com eles. Suas práticas sustentáveis não se devem a uma suposta consciência ecológica, mas a um tipo de organização social secular voltada para a garantia do sustento de suas famílias.

Baseado em material etnográfico sobre os Ashaninka do Acre, um grupo reconhecido como povo modelo entre os povos indígenas, com relação ao desenvolvimento sustentável, e em outros estudos de etnologia indígena amazônica, Pimenta (2004) contribui para o estudo da diversidade de relações entre homem e natureza, mostrando que o desenvolvimento sustentável não é incompatível com as práticas indígenas e pode realmente melhorar seu bem estar, tendo-se em mente que práticas que são entendidas como sustentáveis, tais como a agricultura itinerante e a caça controlada, são parte do universo cognitivo-simbólico deste povo. Laços estreitos

23 "Empate" é um termo nativo que designa ações organizadas para parar, ou "criar um impasse", a derrubada de florestas em áreas de conflito. 
entre caçador e animal caçado definem o princípio regulador da caça e não um pretenso compromisso com a ideologia ocidental do ambientalismo. Contudo, essa retórica ambientalista é utilizada como instrumento político desse povo para viabilizar a obtenção de recursos e de novas alternativas econômicas. A convergência entre essas duas lógicas não se deve puramente à imposição de uma concepção de fora. A boa recepção dos indígenas à ideia do desenvolvimento sustentável se deve a seus próprios esquemas cognitivos: se os Ashaninka caçam de maneira "sustentável" é porque eles temem Manikari e não porque têm consciência ecológica.

\section{A (imposição da) sustentabilidade como fator de reforço da exclusão da agricultura familiar}

Em dissonância com o argumento do caráter sustentável da agricultura familiar, Moreira (1997) e Floriani (2007) levantam uma crítica contra o que consideram uma imposição que se soma a outros tipos de obstáculos à reprodução social enfrentados pelos agricultores familiares. A obrigatoriedade da adoção de práticas sustentáveis seria uma sobrecarga imputada a um segmento da população que já sofre com a desvalorização cultural-ideológica e com a carência de políticas públicas que permitam seu desenvolvimento: carecem historicamente de assistência social e de políticas públicas de desenvolvimento rural, mas [...] são cobrados [...] pela preservação dos recursos naturais (Floriani, 2007, p. 60).

$\mathrm{Na}$ contracorrente da onda verde, Moreira sustenta uma crítica a duas noções centrais do que chama de a contemporaneidade ecológica: a de agricultura de subsistência e a de sustentabilidade. Para ele, noção de agricultura familiar, tal como aparece nos discursos ambientalistas, é informada pela pré-noção cultural-ideológica de agricultura de subsistência, que pressupõe a geração de renda somente para satisfazer as neces- 
sidades imediatas da família, o que impede de se pensar a melhoria das condições de vida dessas famílias. Imagem que seria agravada com a ideia de se imputar a essa forma de produção a característica ou obrigação de uso dos recursos naturais de forma sustentável. Essa proposição seria um impeditivo a se pensar a possibilidade do progresso social da pequena agricultura familiar e de sua reprodução social ampliada (Moreira, 1997).

\section{A sustentabilidade da agricultura e conhecimentos tecnocientíficos}

Já vimos acima que a racionalidade técnica foi apontada como fator de garantia de uma produção agrícola mais pautada na conservação ambiental. Nessa abordagem, o meio ambiente é visto como riqueza ("recursos") e a técnica como um instrumento que permite explorá-lo de maneira menos desgastante, mais poupadora, na medida em que aumenta a produtividade. O uso da tecnologia, no entanto, está normalmente associado à grande produção, o agronegócio, restando saber até que ponto esse modelo é aplicável à agricultura familiar.

Contrapondo-se àqueles majoritários que argumentam a favor da agricultura tradicional baseada no pousio como mais sustentável ambientalmente, Paterniani (2001) defende uma relação positiva entre a agricultura moderna e a conservação do meio ambiente desde que pautada em práticas referenciadas cientificamente. O emprego racional das técnicas, possibilitado pelo avanço da ciência aplicada à agricultura, permitiria um aumento da produtividade dos alimentos, através da melhora da fertilidade do solo, e a redução dos danos ambientais:

Ao longo do tempo, com os avanços científicos, os pesquisadores procuraram incorporar à agricultura novas tecnologias para tornar as plantas cada vez mais eficientes na produção de alimentos, minimizando a sua vulnerabilidade 
às condições adversas, de tal modo que se tornasse possível utilizar racionalmente os recursos naturais disponíveis, preservando, ao mesmo tempo, áreas para a vida silvestre (Paterniani, 2001, p. 1-2).

Contudo, essa racionalidade produtiva (e ambiental) não seria compatível com a produção agrícola familiar designada pelo autor como de subsistência. Revelando uma visão evolucionista, Paterniani propõe a superação dessa forma de produção (a agricultura familiar) na direção de uma agricultura nos moldes empresariais para a superação da miséria permanente. Pautada em critérios econômico-produtivos, essa abordagem deixa de fora as relações sociais implícitas em qualquer forma de produção, sustentando seu argumento exclusivamente na racionalidade técnica promovida pelo progresso científico.

Ao entender que o emprego de conhecimentos científicos e tecnológicos é uma condição imprescindível para a sustentabilidade ambiental da agricultura, Queiroz (2005) se aproxima de Paterniani, com a grande diferença de não opor a racionalidade técnica ao saber tradicional. Queiroz, que se dedica mais a discutir o manejo participativo dos recursos naturais como um caminho para a conservação da biodiversidade, propõe a incorporação dos saberes das populações locais a uma forte base científica para que se alcance a melhoria da qualidade de vida das populações locais, respeitando suas características culturais de maneira compatível com a conservação da biodiversidade. Em suas palavras, uma vez estabelecida esta relação, decorre consequentemente a redução da pressão antrópica sobre o meio ambiente e sobre aquelas espécies nas quais estava anteriormente focalizado quase todo o impacto da ação humana (Queiroz, 2005, p. 190). 


\section{Conclusões}

Ainda que o material de nossa pesquisa não abarque a totalidade da produção brasileira das Ciências Sociais ${ }^{24}$ sobre a relação entre agricultura e biodiversidade, o levantamento realizado permitiu identificar as questões centrais em debate assim como a maneira como o tema vem sendo abordado em um dado período de tempo (1990 a 2010). A partir desses textos acadêmicos publicados nos periódicos mais importantes segundo a classificação do sistema Qualis da Capes, é possível apontar algumas tendências na bibliografia analisada.

Como observamos, a questão que orientou essa revisão bibliográfica não aparece formulada tal e qual pelos artigos selecionados. Contudo verifica-se que o tema está em debate, ainda que indiretamente, por meio de diferentes enunciados mais especificamente voltados para o impacto das chamadas populações tradicionais e povos indígenas na biodiversidade, sobretudo em áreas protegidas. Em outras palavras a preocupação central é de como conservar o meio ambiente mantendo a população local. Tal indagação é motivada pela legislação ambiental brasileira que restringe o uso dos recursos ou mesmo a permanência de moradores em alguns tipos de áreas protegidas. O papel da agricultura nessa relação aparece quando o argumento que defende a compatibilidade desses grupos com a conservação ambiental se volta para as técnicas de manejo agrícola e extrativistas. Nesses casos, as análises já partem de uma concepção prévia sobre a "sustentabilidade" dessas práticas, havendo pouca investigação sobre como elas realmente se processam em contextos sócio-ambientais específicos. Predomina uma visão naturalizada sobre a relação "harmoniosa" das "populações tradicionais" com o meio ambiente, sem estar

24 Grande parte dessa produção é publicada em forma de livros que não foram considerados nessa pesquisa. 
sustentada por evidências empíricas, o que, aliás, foi observado pelos autores de três artigos (Lima et al., 2005; Ferreira, 2004b; Teixeira, 2005). A partir de uma extrapolação linear de resultados de pesquisas em outros contextos empíricos, alguns autores assumem, com pouca mediação (teórica ou empírica), as conclusões sobre a relação de outros grupos com seus ambientes. Esse tipo de abordagem nos conduz à reflexão sobre os limites da generalização de conclusões de pesquisas sociais, o que acrescenta obstáculos à aplicação da abordagem das Políticas Baseadas em Evidências a temas de conteúdo sociológico.

Por que uma questão que está no cerne das preocupações no campo da intervenção política, e com repercussão na sociedade através da mídia e organizações da sociedade civil, não ocupa um espaço equivalente na agenda de pesquisa dos cientistas sociais brasileiros? Só podemos responder essa indagação com outras perguntas. Teriam as Ciências Sociais instrumentos analíticos para tratar adequadamente a questão proposta? Deveríamos esperar que as Ciências Sociais lidassem com conhecimentos oriundos de outras áreas tais como Agronomia e Biologia? Em se tratando de um conceito formulado originalmente no âmbito das Ciências Naturais, qual o sentido que os cientistas sociais conferem à "biodiversidade"? Como este conceito é operacionalizado nesse novo contexto? Seria possível desenvolver a questão proposta para a revisão bibliográfica sem uma abordagem multidisciplinar? Qual seria a contribuição específica das Ciências Sociais sobre esse tema?

Essas inquietações, que surgiram no decorrer da nossa pesquisa, nos levaram à compreensão de que a questão colocada por nós como norteadora de nossa revisão sistemática talvez não tenha sido bem formulada; ela não seria pertinente ao campo das Ciências Sociais, o que explicaria o pequeno número de artigos encontrados que, direta ou indiretamente, apresentem alguma conexão com o nosso tema (18 em 12.295). Ainda 
que se trate de uma questão relevante para a formulação de políticas públicas e para a compreensão da dinâmica de reprodução social de famílias de agricultores, ela só poderia ser respondida através de uma colaboração multidisciplinar, o que teria motivado a autoria conjunta de especialistas em disciplinas da área das ciências naturais e das sociais; somente sete autores têm formação exclusiva na área das Ciências Humanas e Sociais e alguns com formação em mais de uma área.

Deve-se levar em conta também o atraso das Ciências Sociais na incorporação de questões ambientais como objeto de estudo se comparadas às Ciências Naturais. Como os temas relacionados à natureza foram (e são ainda para alguns) percebidos como pertencentes ao domínio das Ciências Naturais, os cientistas sociais só recentemente se voltaram para esse debate. Isso significa que existe ainda um caminho a ser percorrido, no sentido de desenvolver instrumentos analíticos apropriados à análise dos elementos sociais, cada vez mais presente no debate ambiental.

Além disso, observamos que, se o diálogo entre áreas disciplinares se viabilizou, o mesmo não se verificou no interior das Ciências Sociais. É o que pudemos perceber ao constatar a falta de rigor no uso das categorias sociais utilizadas para designar os grupos focalizados em muitos dos artigos analisados - expressão de uma grande lacuna entre a sociologia rural e o que poderíamos chamar, por falta de uma designação melhor, de "sociologia ambiental". A maioria dos autores mantém as denominações nativas ou do senso comum (caiçaras, caipiras, roceiros, sertanejos) ao se referirem aos grupos estudados, sem se preocuparem em qualificá-los sociologicamente. Essa reificação das categorias de uso corrente se soma ao uso de outras noções de pouco alcance e já bastante criticadas como as de pequena produção, pequena agricultura, agricultura local, ou mesmo a da tão questionada população (ou agricultura) tradicional. Essa imprecisão nos termos revela o desconhecimento da extensa contribuição da Socio- 
logia Rural sobre a atribuição de significados à noção de agricultor familiar e de seu similar conceitual, camponês (Wanderley, 2003). O recurso a tais instrumentais analíticos, sem dúvida, teria contribuído para uma análise mais rigorosa e aprofundada.

Se estivermos certas na direção desses questionamentos, o que supõe a necessidade de uma autocrítica, o que dizer então sobre as dificuldades supostamente enfrentadas por um gestor público que fosse buscar apoio na bibliografia sobre essa questão?

A dificuldade de realizar uma síntese a partir de um levantamento bibliográfico criterioso se deve tanto ao tempo necessário para se realizar a busca, que será tanto maior quanto menor for a equipe de trabalho, como também da boa formulação da questão a que se pretende responder. Nem sempre o problema levantado pelos gestores públicos pode ser transposto tal e qual para o campo acadêmico e vice-versa. A formulação de questões para serem sintetizadas a serviço dos formuladores de políticas deve ser feita em conjunto, com a participação de cientistas e políticos, já que é comum a incompatibilidade entre as necessidades dos políticos e as questões tratadas pelos pesquisadores (Hoppe, 2005).

Sobre esse tipo de metodologia vale a pena ponderar sobre os seguintes aspectos: i) a construção dos critérios de levantamento da bibliografia fica condicionada aos instrumentos existentes de busca, disponibilização e seleção da produção acadêmica que se quer acessar; ii) isto, por sua vez, demanda que o indivíduo responsável pela sistematização da bibliografia domine a utilização destes instrumentos e disponha de tempo para elaborar e reelaborar os critérios da pesquisa à medida que as faIhas dos mesmos forem surgindo e as limitações dos recursos de pesquisa disponíveis forem restringindo a possibilidade de se executar a busca de acordo com os critérios elaborados; iii) a produção disponível pode não oferecer, no conjunto, características que facilitem ou até mesmo permi- 
tam uma sistematização que siga fielmente a questão focada pelo levantamento, como, por exemplo, no plano da forma, a ausência de qualquer padrão na estrutura dos artigos, ou, no plano do conteúdo, a ausência de discussões e argumentações especificamente referentes à questão escoIhida para o levantamento; acrescenta-se a ausência de apresentação de demonstrações empíricas dos argumentos.

O tempo necessário e a demanda de mão de obra especializada demonstram que não se trata de uma iniciativa a ser desenvolvida por um único grupo de pesquisa se quisermos tornar as revisões sistemáticas um instrumento útil e operacional para fins de elaboração de políticas baseadas em evidências. Trata-se de uma empreitada que deve ficar a cargo de um Centro de pesquisa específico para esse fim, nos moldes do Centre for Evidence Based Conservation (CEBC) da Universidade de Bangor, ou, alternativamente, sob o domínio público que deve criar meios específicos para elaborar revisões bibliográficas sistematizadas para responder a suas necessidades. O estabelecimento de um espaço institucional para este propósito parece ser o caminho mais eficiente para assegurar um recurso rigoroso ao conhecimento no processo de tomada de decisão pública, de acordo com a abordagem baseada em evidência. Com isso não estamos defendendo que as decisões devem ser baseadas somente em tais conhecimentos, por mais confiáveis que eles possam ser. Trata-se de disponibilizar meios para ampliar o leque de escolha dos formuladores de políticas públicas e de evitar uma relação simplista e cínica entre especialistas e gestores públicos como alguns autores já alertaram (Nutley et al., 2002; Hoppe, 2005) e como a nossa própria pesquisa observou (Da-Silva-Rosa e Carneiro, 2010).

Entretanto, além destas dificuldades operacionais, as ponderações acima apontam para os limites no uso da abordagem das Políticas Baseadas em Evidência visando a facilitar a comunicação entre ciências sociais e políticas públicas. Por exemplo, a elaboração de revisões sistemáticas, 
seguindo os modelos sugeridos pelos especialistas, pressupõe a universalização dos procedimentos científicos sem levar em conta as diferenças das práticas entre os campos de conhecimento. Como mencionamos acima, uma dessas diferenças reside na maneira de apresentar os dados empíricos nos artigos acadêmicos, o que permite questionar o próprio significado de evidência ou prova para as Ciências Sociais. Para respeitar o pluralismo metodológico, talvez seja necessário estabelecer um acordo sobre o que se considera validação empírica em cada questão particular, tal como propuseram Davies et al. (2001). Essa tarefa torna-se ainda mais complexa quando se trata de problemáticas que se situam na interface de diferentes campos do conhecimento, como é o caso das ciências socioambientais, abordadas nesse texto. As Ciências Sociais encontram-se normalmente excluídas da consulta feita por gestores públicos sobre questões ambientais devido à compreensão de que existe uma separação entre natureza e sociedade, de maneira que temas relativos à primeira devam ser tratados por ciências da natureza. Mas acreditamos que essa compreensão se deva também à desvalorização do conhecimento produzido pelos cientistas sociais, decorrente da avaliação de que a validação empírica aí é menos rigorosa do que na Biologia ou na Ecologia, não se distinguindo, portanto, do senso comum.

Finalmente, retomando os artigos da revisão bibliográfica aqui apresentada, cabe destacar os principais resultados da nossa leitura. Dentro da diversidade de abordagens e de universos empíricos trabalhados pelos autores que de alguma maneira tratam da questão por nós levantada - o papel da agricultura familiar na conservação da biodiversidade - destacam-se: a) a imagem de que a agricultura tradicional, praticada por pequenos grupos residentes no interior de áreas protegidas, é uma prática agrícola sustentável; contrapondo-se a essa suposição, que não é empiricamente demonstrada, outros autores vão argumentar que b) a sustentabilidade da agricultura familiar (incluindo a chamada agricultura tradicional) não é intrínseca, dependendo, portanto da conjunção de outros 
fatores; criticando essa posição que estabelece uma relação necessária entre agricultura familiar e sustentabilidade, argumenta-se que c) a imposição da sustentabilidade às atividades dos agricultores familiares é mais um fator, entre muitos, que reforça a sua exclusão dos processos competitivos do mercado; d) já alguns autores argumentam a favor da incorporação de conhecimento técnico-científico nas práticas agrícolas como meio de torná-las sustentáveis; e) finalmente alguns artigos contribuem com a crítica ao estilo ensaístico dos estudos da sociologia ambiental, estimulando a realização de mais pesquisas empíricas para se contrapor às generalizações baseadas em suposições.

\section{Agradecimentos}

Somos gratas ao Conselho Nacional de Desenvolvimento Científico e Tecnológico (CNPq) e à Fundação de Amparo à Pesquisa do Estado do Rio de Janeiro (FAPERJ) pelos recursos para pesquisa concedidos a Maria José Carneiro, e à Agence Nationale de la Recherche (ANR) da França, pelo apoio financeiro.

\section{Referências}

BALÉE, W. Indigenous Adaptation to Amazonian Palm Forests. Principles, v. 32, n. 2, p. 47-54, 1988.

BALÉE, W. Cultura na vegetação da Amazônia brasileira. In: NEVES, W. (org.) Biologia e ecologia humana na Amazônia: avaliação e perspectivas. Belém: SCT/PR/ Cnpq - Museu Paraense Emílio Goeldi. Coleção Eduardo Galvão, p. 95-109, 1989. CARNEIRO, M.J., Política pública e agricultura familiar: uma leitura do Pronaf. Estudos, Sociedade e Agricultura, n. 8, p.70-81, 1997.

CARNEIRO, M .J., GUEDES-BRUNI, R., LEITE, S. Conhecimento científico e políticas públicas: mobilização e apropriação do saber em medidas de conservação da Mata Atlântica. Estudos Sociedade e Agricultura, v.17, n. 2, p. 254-303, 2009. 
CENTRE FOR EVIDENCE-BASED CONSERVATION. Guidelines for Systematic Review in Conservation and Environmental Management. School of the Environment \& Natural Resources. Bangor University, 2009.

DA-SILVA-ROSA, T., CARNEIRO, M .J. O acesso livre à produção acadêmica como subsídios para políticas públicas: um exercício sobre o Banco de Teses da CAPES. História, Ciências, Saúde, v.17, n. 4, p.955-974, 2010.

DA-SILVA-ROSA, T., CARNEIRO, M .J., GUEDES-BRUNI, R., SILVA, A. (in press). Natural Sciences and Social Sciences: Dialogues on knowledge production concerning biodiversity conservation and agriculture in Brazil. In: BUREL, F., LAURENT, C., Plurality of science for interdisciplinarity and policy making: Theoretical findings from analyses of sustainable development in agriculture. London: Bentham E-books.

DAVIES, H. T. O., NUTLEY, S. M., Evidence-based policy and practice: moving from rhetoric to reality. Third International, Inter-disciplinary Evidence-Based Policies and Indicator Systems Conference, 2001.

DIEGUES, A. C. O mito moderno da natureza intocada. São Paulo: Hucitec, 1996.

FERREIRA, L. Idéias para uma sociologia da questão ambiental: teoria social, sociologia ambiental e interdisciplinaridade. Desenvolvimento e Meio Ambiente, n. 10, p. 77-89, 2004a.

FLORIANI, N. O planejamento do espaço rural periurbano:da abordagem funcional do tyerritório às territorialidades da autonomia. Desenvolvimento e Meio Ambiente. n. 16, PP. 55-68 jul-dez, 2007

FUNTOWICS, S., RAVETZ, J. Ciência pós-normal e comunidades ampliadas de pares face aos desafios ambientais. História, Ciências, Saúde. Rio de Janeiro, v. IV, n. 2, p. 219-330, 1997.

GERHARDT, C. H., Pesquisadores, Populações Locais e Áreas Protegidas: entre a instabilidade dos "lados" e a multiplicidade estrutural das "posições". Tese (Doutorado em Ciências Sociais em Desenvolvimento, Agricultura e Sociedade), CPDA/UFRRJ, Rio de Janeiro. 2008.

GOMESZ-POMPA, KAUS, A. Traditional management of tropical forest in México. In: ANDERSON, A. B (ed). Alternative to deforestation: steps to ward sustainable use of the Amazon rain. New York: Columbia University Press, p. 45-64, 1990.

HARDIN, G. The tragedy of the commons. Science, n.162, p. 1243-1248, 1968.

HARWOOD, R. Development pathways toward sustainable systems following slash-and-burn. Agricultural Systems \& Environment, n. 58, p. 75-86, 1996. 
HOLMES, J., CLARK, R. Enhancing the use of science in environmental policymaking and regulation. Environmental Sicence \& Policy, v. II, p. 702-711, 2008. HOPPE, R., Rethink the science-policy nexus: from knowledge utilization and science technology studies to types of boundary arrangements. Poiesis Prax. n. 3, p. 199-215, 2005.

LAURENT, C., LABARTHE, P., TROUVÉ, A., BERRIET-SOLLIEC, M., BONNAFOUS, P. Les connaissances scientifiques et techniques : une ressource de plus en plus rare pour la décision publique? Communication for the Forum of the Regulation. Paris: École Normale Supérieure/Maison des Sciences Economiques Paris-Sorbonne, 2009a.

LAURENT, C., TROUVÉ, A, PERRAUD, D. A emergência do debate sobre as abordagens Evidence-based ou Evidence-aware policy no campo da agricultura. Estudos Sociedade e Agricultura, v. 17, n. 2, p. 193-226, 2009 b.

LAURENT, C. Validité des connaissances scientifiques et intervention publique : le cas de l'agriculture dans le développement durable (EBP-BIOSOC). Paris: ANR Research Project, INRA, 2006.

LEFF, E. Epistemologia Ambiental. São Paulo: Cortez, 2001.

LEONARD, E., BONNAL, P., FOYER, J., LEITE, S.P. La construction normative Du développement durable dans les contexts de sa "mise en politiques". Une analyse par les dépendances de sentier au Brésil e au Mexique. Mondes em Développement, v. 37, n. 148, 2009.

NEVES, F. O. C. Os guaranis invadem o Parque Estadual Intervales : como destruir a biodiversidade sendo politicamente correto. ADCOAS-IBAP Revista de Direitos Difusos, v. 20 Ocupação territorial e meio ambiente I, p. 2719-2748, jul/ago. 2003.

NUTLEY, D. et all. Evidence Based Policy and Practice: cross sector lessons from the UK. ESRC UK Centre for Evidence Based Policy and Practice: Working Paper 9, 2002.

OSTROM, E. Governing the commons: the evolution of institutions for collective action. New York: Cambridge University Press, 1990.

POSEY, D. A. 1986. Manejo da floresta secundária, capoeiras e cerrados (Kayapó). In: Ribeiro, B. (org). Suma Etnológica Brasileira (1): Etnobiologia. Petrópolis: FINEP/Vozes, 1986.

PULLIN, A. S., STEWART, G. B., Guidelines for Systematic Review in Conservation and Environmental Management. Conservation Biology., v. 20, n. 6, p. 16471656, 2006. 
SUTHERLAND, W.; PULLIN, A.S.; DOLMAN, P.M.; KNIGHT, T.M. The need for evidence based conservation. Trends in Ecology and Evolution, v.19, n.6, june, 2004.

UNESCO. 2010. World Social Science Report. Disponível em: <http://www. unesco.org/new/en/social-and-human-sciences/resources/reports/world-socialscience-report>. Acesso em: 30 ago 2010.

WANDERLEY, M. N. Agricultura familiar e campesinato: rupturas e continuidade. Estudos, Sociedade e Agricultura, v. 21, p. 42-61, out. 2003.

Referências da bibliografia revisada:

ALLEGRETTI, M. A construção social de políticas públicas. Chico Mendes e o movimento dos seringueiros. Desenv. e Meio Amb. n. 18, p. 39-59, jul/dez. 2008. ALMEIDA, L. Elementos para pensar a transição agroambiental: as lógicas da mudança técnica na agricultura familiar. Desenv. e Meio Amb. n.14, p. 33-45, jul/ dec. 2006.

ARRUDA, R., "Populações tradicionais" e a proteção dos recursos naturais em unidades de conservação. Ambient. Soc., n. 5, p. 79-92, jul-dec. 1999.

AZEVEDO, A.I., MARTINS, H.T., DRUMMOND, J.A., A dinâmica institucional de uso comunitário dos produtos nativos do cerrado no município de Japonvar (Minas Gerais). Brasília, v. 24, n. 1, p. 193-228, jan./abr. 2009.

BRANDENBURG, A., FERREIRA, A. D. D., SANTOS, L. J. C., Dimensões socioambientais do rural contemporâneo. Desenv. e Meio Amb. n. 10, p. 119-125, jul/ dez. 2004.

CASTRO, F., SIQUEIRA, A. D., BRONDIZIO, E. S., FERREIRA, L., Uso e abuso dos conceitos de tradição e direitos de propriedade na conservação de recursos naturais na Mata Atlântica, Brasil. Ambient. Soc., v. 9, n. 1, p. 23-39, 2006.

DUMORA, C. Viver e sobreviver numa Área de Proteção Ambiental: o caso da pequena agricultura familiar em uma das comunidades rurais da APA de Guaraqueçaba. Desenv. e Meio Amb. n. 14, p. 47-67, jul/dec. 2006.

FERREIRA, L. C. Dimensões humanas da biodiversidade: mudanças sociais e conflitos em torno de áreas protegidas no Vale do Ribeira, SP, Brasil. Ambient. Soc., v.7, n. 1, p. 47-66, 2004 b. 
LIMA, D., POZZOBON, J., Amazônia socioambiental: sustentabilidade ecológica e diversidade social. Estud. av. v. 19, n. 54, p. 45-76, 2005.

MARTINS, P. Dinâmica evolutiva em roças de caboclos amazônicos. Estud. av., v. 19, n. 53, p. 209-220, 2005.

MOREIRA, R. Agricultura familiar e sustentabilidade: valorização e desvalorização econômica e cultural das técnicas. Est. Soc. e Agric., n. 8, 1997.

MOTA, D. M. J., SANTOS, V. Uso e conservação dos remanescentes de mangabeira por populações extrativistas em Barra dos Coqueiros, Estado de Sergipe. Acta Scientiarium. Human and Social Sciences. Maringá, v. 30, n. 2, p. 173-180, 2008.

PATERNIANI, E. Agricultura sustentável nos trópicos. Estud. av., v. 15, n. 43, p. 303-326, 2001.

PEDLOWSKI, M.; DALE,V.; MATRICARDI,G. A criação de área protegidas e os limites da conservação ambiental em Rondônia. Ambiente \& Sociedade - Ano II - n. 5 - 2o Semestre de 1999.

PIMENTA, J. Desenvolvimento sustentável e povos indígenas: os paradoxos de um exemplo amazônico. Anuário Antropológico, 2002/2003, 2004.

QUEIROZ, H. L. A reserva de desenvolvimento sustentável Mamirauá. Estud. av., v.19, n. 54, p. 183-203, 2005.

RODRIGUES, A., TOMMASINO, H., FOLADORI, G. É correto pensar a sustentabilidade em nível local? Uma análise metodológica de um estudo de caso em uma Área de Proteção Ambiental no litoral sul do Brasil. Ambient. soc., v. 6, n. 1, p. 109-127, 2003.

SILVA, C. E. M. Ordenamento Territorial no Cerrado brasileiro: da fronteira monocultora a modelos baseados na sociobiodiversidade. Desenv. e Meio Amb. n.19, p. 189-109, jan/jun. 2009.

TEIXEIRA, C. O desenvolvimento sustentável em unidade de conservação: a "naturalização" do social. Rev. bras. Ci. Soc., v.20, n. 59, p. 51-66, 2005. 